\title{
Factors Determining Nurses Hospital Information System Usage
}

\author{
Hesamaddin Kamalzadeh Takhti ${ }^{1}$, Azizah Binti Abdul Rahman ${ }^{2}$, Samireh Abedini ${ }^{3}$ \\ ${ }^{1}$ Department of information system, Faculty of Computing, Universiti Teknologi Malaysia \\ ${ }^{2}$ Associate. Professor, Department of information system, Faculty of Computing, University Teknologi Malaysia \\ ${ }^{3}$ Department of educational foundations, Faculty of Education, Universiti Teknologi Malaysia and Faculty \\ member of Hormozgan University of medical sciences
}

\begin{abstract}
This study employs the combined technology acceptance model (TAM) and theory of planned behavior (TPB) (i.e., CTAM-TPB) that extended with self-efficacy and knowledge of information technology to examine HIS acceptance by Malaysian nurses. A cross-sectional survey was conducted in three public hospitals in Malaysia to gather data from practicing nurses with experience of using HIS. Structural equation modeling using the partial least squares (PLS) method was utilized to evaluate measurements and structural models. The results stress that a nurse's intention was significantly influenced by three factors, including his or her attitude, the subjective norm, and perceived behavioral control. The results also indicate that the model can explain over half of the variance in the intention to use HIS.
\end{abstract}

Keywords: nursing, hospital information system(s), technology acceptance model, theory of planned behavior, knowledge, self-efficacy.

\section{INTRODUCTION}

The healthcare system in Malaysia is becoming substantially more accepted, and use of HIS is gaining increasing importance with advances in information systems generally. The implementation of HIS is considered a prerequisite for improving the quality of patient care, and essential in meeting the associated diagnostic, treatment and administration requirements [1]. However, low utilization of installed systems has been identified as a major factor in implementing HIS [2]. Although HIS has led to a change in the process of care delivery and has also helped to improve the quality and safety of care [3,4], compared to other technologies in the healthcare domain it has been adopted relatively slowly [5]. Since using existing HIS in Malaysian public hospitals is mandatory, it can be assumed that use of HIS in this context is expected among nurses when performing their responsibilities [6]. However, making HIS mandatory has not in itself been sufficient in enticing its use in nurses' daily work [7]. Unfortunately, the major problem that has come to light in Malaysian healthcare is that nurses are unwilling to integrate HIS into their workflow [8,9]. Given that the adoption and use of IT has been a significant problem in healthcare [10], this study attempts to explain the issues involved, and will hopefully contribute to this limited body of knowledge while promoting the use of HIS in nursing.

\section{LITERATURE REVIEW}

\subsection{Hospital Information System (HIS)}

The healthcare industry is considering a wide variety of emerging information technologies applications in an effort to enable the key players, health professionals, access to general and specific the patient's information for improving efficiency and quality of patient care [11]. In clinical practice, some problems have been addressed via the implantation of HIS. For example, through the use of a HIS nurses are able to track the patient's care electronically. Clinical activities such as nursing documentation also stand to benefit from HIS [12,13]. Hence, the involvement of nurses in the use of HIS is the most important factor, and a constant issue in acceptance of IT [14]. Nurses can better appreciate the advantages of technology if they accept and integrate said technologies into their daily work [15]. Acceptance of HIS by the largest elements within the healthcare system [16] therefore allows healthcare organizations to significantly enhance the delivery of care. Nurses generally have a positive attitude toward computers [17], but they are reluctant to accept and utilize HIS in their daily work [9, 18]. Hence, an empirical study was conducted to understand nurses' acceptance of the HIS for practicing nursing care. Recent studies have investigated the factors affecting IT acceptance by healthcare professionals via various ISs, such as the Medline system [10] Mobile healthcare [19] Healthcare information system [20] Electronic health care records system [21] Clinical information systems [22]. Compared with the earlier studies mentioned above, this study highlights one specific question: what are the factors driving nurses' usage intention of the HIS in the nursing care?

\subsection{Technology Acceptance Model (TAM) and Theory of planned behavior (TPB)}

Technology acceptance is an important area of research in healthcare [10], and researchers adopt many different methods to adequately assess the acceptance of IT by users. Among the variety of models that have been advanced to give a clearer view on the acceptance and use of technology, TAM and TPB describe more in-depth understanding of behavioral intention [23]. TAM [24] is a well-accepted intention model [25] that increasingly utilized as an appropriate model [26] for explaining the acceptance and use of IT in terms of behavioral intention to use and system usage [27]. Many studies have tested TAM in healthcare [19-22, 28, 29] and shown it to be a fitting theory, but studies have not fully covered both technological and behavioral aspects [19] in the healthcare domain specifically. Even though TAM has played a significant role as the predictor of intention to use technology [30], it is not generally regarded as a theoretical background in certain disciplines [31]. The model also neglects the influence of social and control factors. Social variables and behavioral controls, lacking in TAM [32], are the key determinants of behavior in TPB [33]. TPB is one of the important cognitive models for a more appropriate prediction and interpretation of behavior [34] that well tested in the field of IT in 
terms of describing an individual's acceptance and use of technology [35]. TAM and TPB have been successfully implemented in a wide variety of settings regarding individual acceptance and usage of different kind of ISs [36]; therefore, an integration of these theories can be as a complementary style [37] that lead to higher power to predict the acceptance and use of IT by individual professionals [19, 38, 39]. For example, upon comparing TAM, TPB and C-TAM-TPB in understanding the physicians' usage of telemedicine, Chau and $\mathrm{Hu}$ [39] reported that the explanatory power of C-TAMTPB is better than TAM and TPB. Thus, this study adopted the C-TAM-TPB (Fig.1) to explain nurses' acceptance of the HIS in nursing care.

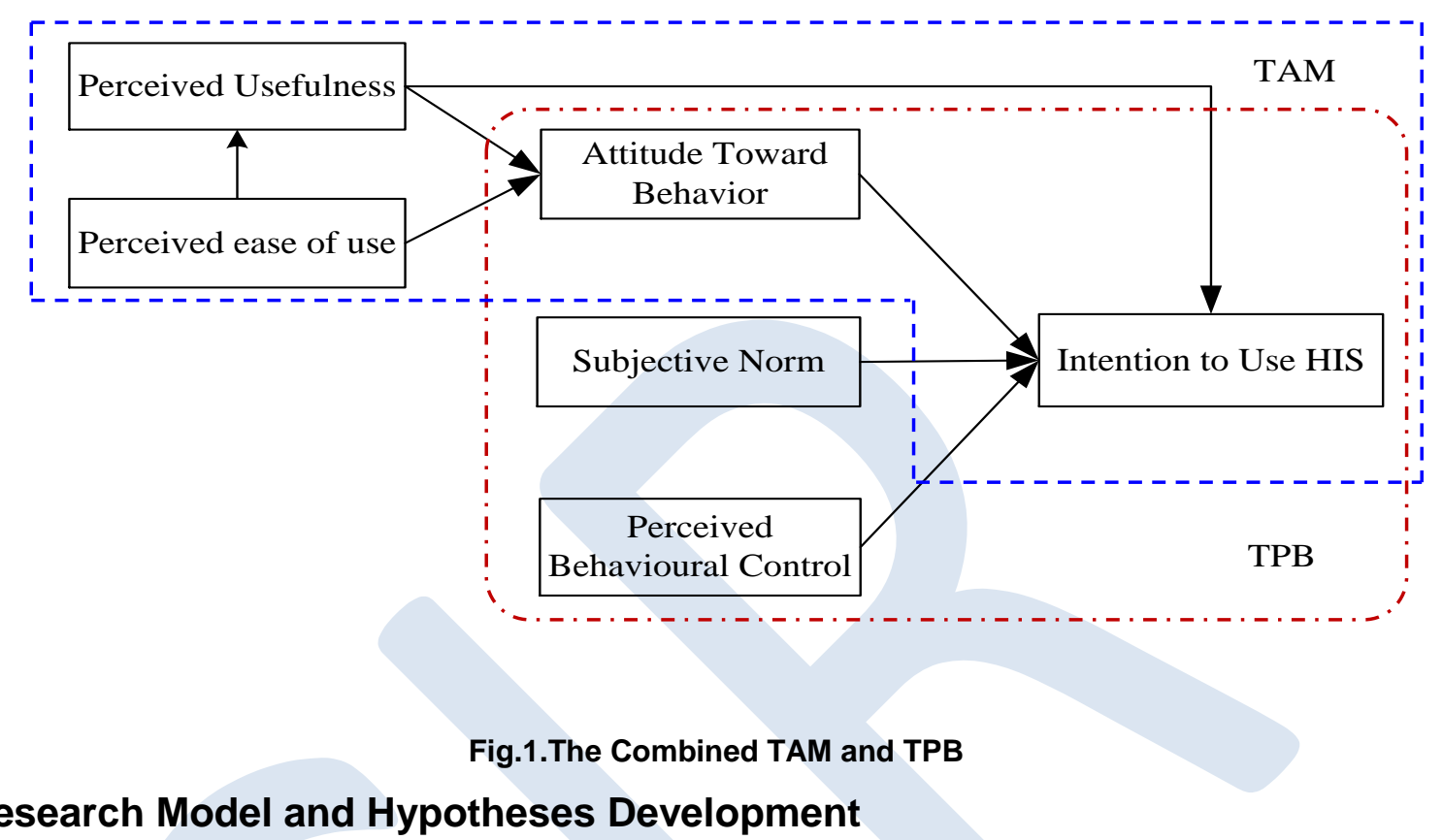

\subsection{Research Model and Hypotheses Development}

The combined TAM and TPB model (C-TAM-TPB) proposed by Taylor and Todd [40] adopts concepts from both TAM and TPB, in order to be more effective [37] and provide additional explanatory power [41]. Moreover, to understand the underlying factors that affect nurses' usage intention of HIS and to modify the proposed model, an in-depth interview with head nurses has conducted. The results of interviews and the existing literature therefore suggests that we could gain a better understanding of the factors explaining the use of the HIS in nursing care by employing two additional constructs, namely knowledge and self-efficacy. The constructs and their hypothesized relationships are depicted in Fig. 2.

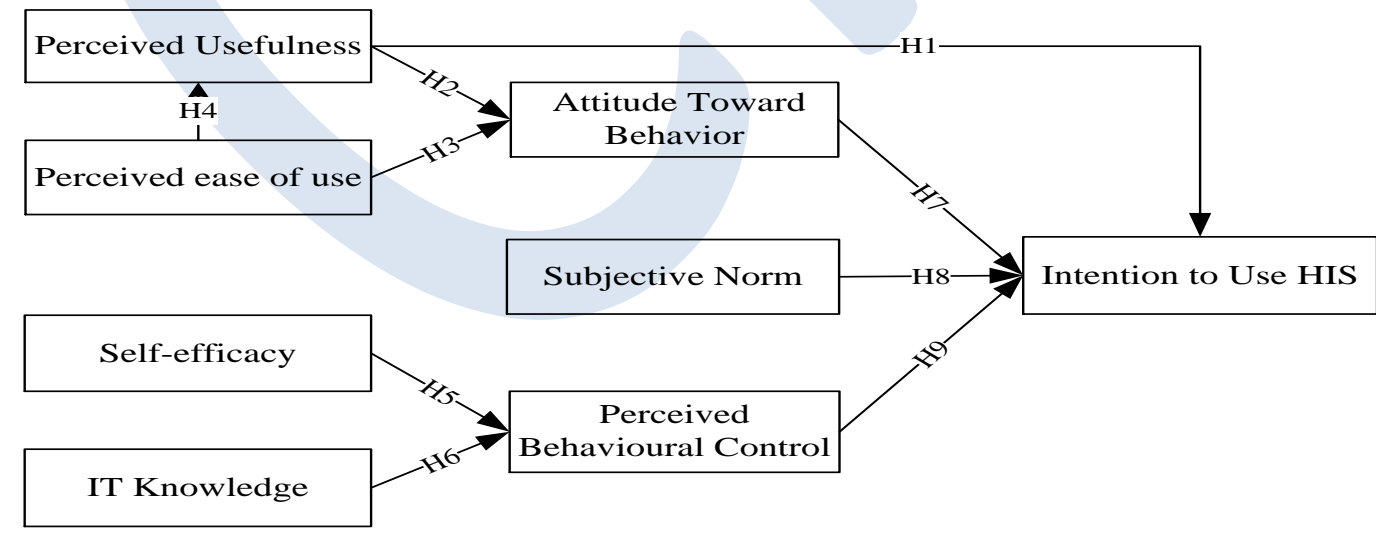

Fig.2. Theoretical framework and hypotheses

In the original TAM, perceived usefulness, which defined as "the degree to which a person believes that using a particular system would enhance his or her performance" [42] is the determinant of both attitude toward behavior and intention to use. Reviews of previous studies show the potential importance of perceived usefulness in determining health care professional attitudes and their intention to use IT applications [10, 19-22]. In addition, perceived ease of use, which refers to "the degree to which a person believes that using a particular system would be free of effort" is a predictor of perceived usefulness and attitude [42]. In health care, studies have found the indirect effect of perceived ease of use on technology acceptance, through usefulness and attitude [10,19, 21]. Therefore, based on above relevant articles we hypothesized:

H1. Perceived usefulness has a positive effect on nurses' intentions to use HIS

H2. Perceived usefulness has a positive effect on nurses' attitudes

H3. Perceived ease of use has a positive effect on nurses' attitudes 
H4. Perceived ease of use has a positive effect on perceived usefulness

In exploring the effective factors for the acceptance of online stock trading, Abroud et al. [43] mentioned that knowledge about IT has meaningful relationships with perceived behavioral control. We can expect that nurses' basic IT knowledge should have a significant positive effect on the control that they can exercise in their jobs [43], because sufficient knowledge of using an information system is the key variable to improving a nurse's IT skills [44]. However, knowledge barriers to initial HIS adoption by nurses may be interpreted as computer self-efficacy, which is an important determinant of behavior control [43]. Self-efficacy refers to "judgment of one's ability to use a technology to accomplish a particular job or task" [36]. Previous research [36] has shown that self-efficacy did not has any direct effect on intention, however, affect it indirectly through behavioral control $[10,43,45]$. Thus, the following hypotheses are put forth:

H5. Self-efficacy has a positive effect on nurses' perceived behavioral control

H6. IT Knowledge has a positive effect on nurses' perceived behavioral control

TPB suggests three conceptually independent determinants of intention. The first is the attitude towards behavior that refers to "an individual's positive or negative feelings about performing the target behavior"[46]. As is apparent from the literature, the role of attitude in explaining acceptance of IT is widely recognized. In particular, health studies have highlighted the importance of attitude in predicting intention to use health-related ISs [19, 21, 22]. Hence, this relationship is hypothesized as follows:

H7. Nurses' attitudes have a positive effect on nurses' intentions to use HIS

The second predictor is subjective norm; it refers to "the perceived social pressure to perform or not to perform the behavior"[33]. Venkatesh and Davis [47] found that in mandatory usage contexts subjective norm has a direct effect on intention. Hung et al. [10] used decomposed TPB to investigate the factors influencing physicians' acceptance of the Medline system. The results of their studies show that subjective norm has significant impacts on intention. Based on the above results, hypothesis $8(\mathrm{H} 8)$ is presented as follows:

H8. The subjective norm has a positive effect on nurses' intentions to use HIS

The third antecedent of intention is the level of perceived behavioral control which refers to "the perceived ease or difficulty of performing the behavior" [33]. A substantial number of studies, especially in the healthcare setting, have documented the significant effect of perceived behavioral control on intention [10,19]. Based on above relevant articles, the following hypothesis is put forward as follows:

H9. Perceived behavioral control has a positive effect on nurses' intentions to use HIS

\section{METHODS}

In this study, conducted in three Malaysian public hospitals, a quantitative approach was applied. In this approach, a questionnaire designed to capture information about the constructs in the research model was employed. The five-point Likert scale was used to measure each construct's indicators. Based on a simplified formula [n=N/1+N(e2)] provided by Yamane [48], where " $n$ " is the sample size; " $N$ " is the population size and "e" specifies the desired level of precision (e=1precision), 342 full-time practicing nurses were selected by using simple random sampling. Data collection was conducted using a cross-sectional survey by means of a self-administered questionnaire.

The evaluation of the measurement model and the structural model was performed by structural equation modeling (SEM) which has been widely applied in healthcare studies [19-22]. To evaluate the measurement model and the structural model simultaneously, partial least square (PLS) was performed. Hence, first, PLS algorithm procedure was performed to assess the quality of the measurement model by reliability and validity (convergent and discriminant) of constructs [49]. Then, the evaluation of the structural model was carried out by the assessment of coefficient of determination (R2), which shows the model's ability to explain and predict the dependent latent variables [50], and significance of path coefficients $[49,51]$. To assess the statistical significance of each path coefficient between the latent variables of the research model, the bootstrapping procedure with 500 subsamples (as recommended by Chin [52]) was performed. Consequently, based on the evaluated structural model, the hypotheses can be considered as either confirmed or rejected.

\section{DATA ANALYSIS AND RESULTS}

We distributed exactly 342 questionnaires among full-time practicing nurses, who were selected by simple random sampling in various wards of three Malaysian public hospitals. Data collection was conducted using a cross-sectional survey by means of a self-administered questionnaire. In total, 321 responses were collected; a $94 \%$ response rate. To analyse the data, the research model was operationalized and transferred into an SEM and then the PLS approach was applied.

\subsection{Sample Demographics}

The majority of respondents to this study $(98.8 \%)$ were female. $67.3 \%$ of respondents consisted of nurses under the age of 30 . Most of the nurses in the sample (87.2\%) had a nursing diploma. $66.4 \%$ of the respondents had used the HIS for more than two years, while $27.4 \%$ had six months to two years of experience with the system. $48.9 \%$ of respondents used the system in nursing for more than 40 minutes per shift; $42.1 \%$ of respondents worked with the system for between 20 and 40 minutes per shift.

\subsection{Measurement Model Analysis}

The measurement model was evaluated based on the reliability and validity of constructs. The reliability of each construct was assessed by examining the composite reliability and internal consistency reliability (Cronbach's alpha). Table 1 shows that the values of Cronbach's alpha and composite reliability are above the acceptable level of 0.70 , indicating that the measurement errors were relatively small $[51,53]$. The validity of constructs was assessed by evaluating the convergent 
validity of each scale and discriminant validity between the constructs. First, an examination of items' factor loading and average variance extracted (AVE) $[53,54]$ was conducted to explore the convergent validity of the scales used in this study. The results show (Table 2) that values for item loading on underlying constructs are more than 0.70 . Furthermore, the AVE values of all constructs (Table 2) are above 0.5 , indicating that the convergent validity is assumed [53].

Table 1.Cronbach's alpha (CA), Composite Reliability (CR), average variance extracted (AVE); diagonal elements are the square root of AVE; off-diagonal elements are correlations between constructs $(\mathrm{N}=321)$.

\begin{tabular}{lrrrcccccccc}
\hline \hline & CA & CR & AVE & BI & K & ATB & PBC & PEU & PU & Se & SN \\
BI & 0.828 & 0.880 & 0.595 & $\mathbf{0 . 7 7 1}$ & & & & & & & \\
K & 0.782 & 0.859 & 0.604 & 0.554 & $\mathbf{0 . 7 7 7}$ & & & & & & \\
ATB & 0.887 & 0.918 & 0.691 & 0.605 & 0.355 & $\mathbf{0 . 8 3 1}$ & & & & & \\
PBC & 0.769 & 0.843 & 0.519 & 0.599 & 0.707 & 0.503 & $\mathbf{0 . 7 2 0}$ & & & & \\
PEU & 0.826 & 0.878 & 0.590 & 0.338 & 0.357 & 0.373 & 0.342 & $\mathbf{0 . 7 6 8}$ & & & \\
PU & 0.887 & 0.917 & 0.689 & 0.362 & 0.238 & 0.513 & 0.332 & 0.536 & $\mathbf{0 . 8 3 0}$ & & \\
Se & 0.862 & 0.905 & 0.704 & 0.364 & 0.238 & 0.521 & 0.338 & 0.494 & 0.582 & $\mathbf{0 . 8 3 9}$ & \\
SN & 0.751 & 0.842 & 0.573 & 0.484 & 0.276 & 0.325 & 0.368 & 0.164 & 0.285 & 0.291 & $\mathbf{0 . 7 5 7}$ \\
\hline \hline
\end{tabular}

Note: $\mathrm{BI}=$ Behavioral intention, $\mathrm{K}=$ Knowledge, $\mathrm{ATB}=$ Attitude toward behavioral, $\mathrm{PBC}=$ Perceived behavioral control, $\mathrm{PEU}=$ Perceived Ease of Use, $\mathrm{PU}=$ Perceived Usefulness, $\mathrm{Se}=$ Self-efficacy, $\mathrm{SN}=$ Subjective Norm

Second, discriminant validity can be assessed through the analysis of correlations among constructs, and can be ensured when the correlations among all constructs in the model below the 0.85 threshold $[55,56]$ and the square roots of the AVE of each construct are larger than the inter-construct correlations [53]. Results showed adequate discriminant validity for all constructs in our research model (see Table 2). Therefore, based on the results of reliability and validity of constructs, measurement models were successfully validated.

Table 2.Loadings and cross-loadings of individual on their constructs $(N=321)$.

\begin{tabular}{|c|c|c|c|c|c|c|c|c|}
\hline & BI & ITK & NA & PBC & PEU & PU & SE & SN \\
\hline Bl1 & 0.765 & 0.465 & 0.419 & 0.551 & 0.342 & 0.309 & 0.298 & 0.307 \\
\hline $\mathrm{BI} 2$ & 0.826 & 0.418 & 0.546 & 0.505 & 0.260 & 0.364 & 0.376 & 0.421 \\
\hline $\mathrm{BI} 3$ & 0.832 & 0.448 & 0.545 & 0.470 & 0.192 & 0.246 & 0.255 & 0.384 \\
\hline BI4 & 0.747 & 0.394 & 0.392 & 0.337 & 0.288 & 0.210 & 0.204 & 0.339 \\
\hline BI5 & 0.775 & 0.406 & 0.397 & 0.418 & 0.236 & 0.246 & 0.246 & 0.409 \\
\hline K1 & 0.439 & 0.780 & 0.305 & 0.605 & 0.306 & 0.194 & 0.190 & 0.249 \\
\hline K2 & 0.399 & 0.821 & 0.221 & 0.509 & 0.212 & 0.095 & 0.104 & 0.193 \\
\hline K3 & 0.460 & 0.765 & 0.237 & 0.545 & 0.322 & 0.193 & 0.186 & 0.234 \\
\hline K4 & 0.419 & 0.742 & 0.334 & 0.528 & 0.261 & 0.252 & 0.256 & 0.175 \\
\hline NA1 & 0.471 & 0.278 & 0.833 & 0.437 & 0.244 & 0.425 & 0.437 & 0.258 \\
\hline NA2 & 0.485 & 0.277 & 0.861 & 0.429 & 0.319 & 0.438 & 0.447 & 0.278 \\
\hline NA3 & 0.521 & 0.308 & 0.850 & 0.412 & 0.321 & 0.431 & 0.436 & 0.298 \\
\hline NA4 & 0.549 & 0.312 & 0.844 & 0.401 & 0.356 & 0.430 & 0.434 & 0.295 \\
\hline NA5 & 0.481 & 0.298 & 0.762 & 0.414 & 0.304 & 0.408 & 0.408 & 0.217 \\
\hline PBC1 & 0.484 & 0.609 & 0.380 & 0.711 & 0.206 & 0.177 & 0.184 & 0.265 \\
\hline PBC2 & 0.449 & 0.452 & 0.381 & 0.725 & 0.267 & 0.267 & 0.271 & 0.330 \\
\hline PBC3 & 0.338 & 0.439 & 0.263 & 0.719 & 0.224 & 0.219 & 0.229 & 0.238 \\
\hline PBC4 & 0.448 & 0.488 & 0.387 & 0.774 & 0.274 & 0.271 & 0.272 & 0.258 \\
\hline PBC5 & 0.416 & 0.530 & 0.382 & 0.798 & 0.264 & 0.268 & 0.266 & 0.233 \\
\hline PEU1 & 0.244 & 0.249 & 0.300 & 0.260 & 0.778 & 0.473 & 0.425 & 0.112 \\
\hline PEU2 & 0.212 & 0.216 & 0.273 & 0.197 & 0.792 & 0.378 & 0.345 & 0.092 \\
\hline PEU3 & 0.259 & 0.281 & 0.284 & 0.265 & 0.804 & 0.363 & 0.333 & 0.118 \\
\hline PEU4 & 0.246 & 0.277 & 0.279 & 0.261 & 0.704 & 0.337 & 0.318 & 0.110 \\
\hline PEU5 & 0.329 & 0.342 & 0.292 & 0.321 & 0.757 & 0.475 & 0.450 & 0.187 \\
\hline PU1 & 0.293 & 0.155 & 0.414 & 0.242 & 0.382 & 0.813 & 0.217 & 0.253 \\
\hline PU2 & 0.289 & 0.169 & 0.472 & 0.292 & 0.432 & 0.840 & 0.356 & 0.265 \\
\hline PU3 & 0.333 & 0.269 & 0.459 & 0.344 & 0.399 & 0.813 & 0.363 & 0.224 \\
\hline PU4 & 0.302 & 0.186 & 0.390 & 0.229 & 0.459 & 0.846 & 0.220 & 0.241 \\
\hline PU5 & 0.287 & 0.204 & 0.395 & 0.267 & 0.542 & 0.839 & 0.425 & 0.203 \\
\hline S1 & 0.293 & 0.155 & 0.414 & 0.242 & 0.382 & 0.413 & 0.817 & 0.253 \\
\hline S2 & 0.289 & 0.169 & 0.472 & 0.292 & 0.432 & 0.440 & 0.856 & 0.265 \\
\hline S3 & 0.333 & 0.269 & 0.459 & 0.344 & 0.399 & 0.213 & 0.863 & 0.224 \\
\hline S4 & 0.302 & 0.186 & 0.390 & 0.229 & 0.459 & 0.346 & 0.820 & 0.241 \\
\hline SN1 & 0.400 & 0.235 & 0.287 & 0.324 & 0.175 & 0.185 & 0.197 & 0.743 \\
\hline SN2 & 0.324 & 0.211 & 0.213 & 0.280 & 0.103 & 0.236 & 0.237 & 0.704 \\
\hline
\end{tabular}




\begin{tabular}{lllllllll} 
SN3 & 0.389 & 0.214 & 0.221 & 0.230 & 0.113 & 0.220 & 0.221 & $\mathbf{0 . 8 0 4}$ \\
SN4 & 0.344 & 0.173 & 0.258 & 0.279 & 0.097 & 0.227 & 0.230 & $\mathbf{0 . 7 7 2}$ \\
\hline
\end{tabular}

Note: $\mathrm{Bl}=$ Behavioral intention, $\mathrm{K}=$ Knowledge, $\mathrm{ATB}=$ Attitude toward behavioral, $\mathrm{PBC}=$ Perceived behavioral control, $\mathrm{PEU}=$ Perceived Ease of Use, $\mathrm{PU}=$ Perceived Usefulness, $\mathrm{Se}=$ Self-efficacy, $\mathrm{SN}=$ Subjective Norm

\subsection{Structural Model Analysis}

The coefficient of determination (R2) and the statistical significance of each path coefficient were applied to examine the causal relationship between constructs in the model $[49,51]$. In the current research model, attitude toward behavior explains about $38 \%$ of the variance in perceived usefulness and perceived ease of use. Moreover, perceived behavioral control explains $53 \%$ of the variance in knowledge and self-efficacy. Consequently, the model explains almost $54 \%$ of the variance in behavioral intention (Fig.3).

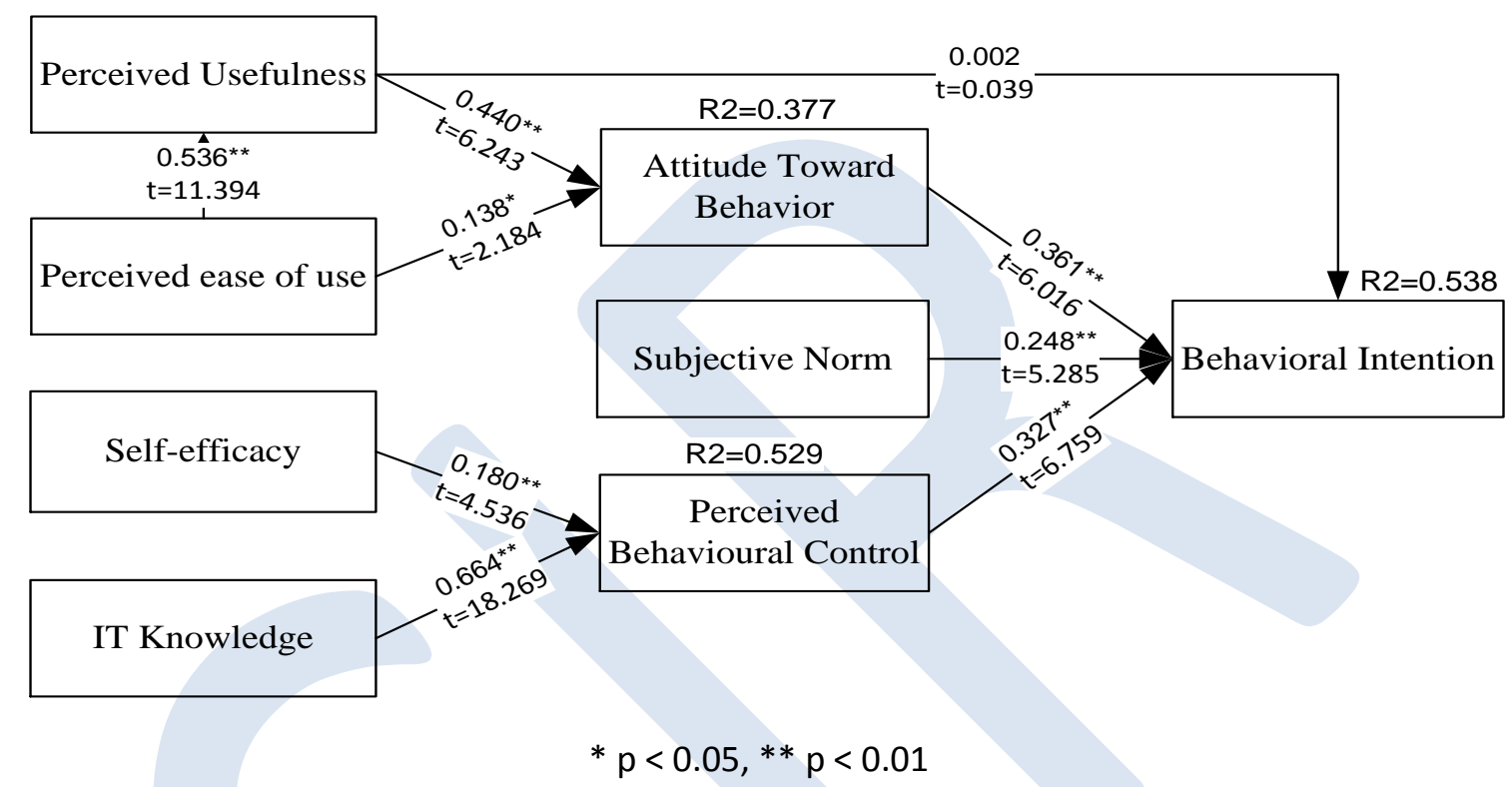

Fig.3. Results of PLS analysis

\section{DISCUSSION}

The purpose of the study was to examine HIS acceptance by Malaysian nurses, and develop a model of technology acceptance among this group of health professionals. The results showed that the predictive power of factors was considerable and represented over half of the variance in the intention to use HIS (R2 = 0.538), implying that the model could effectively explain the acceptance of HIS by nurses. The result is consistent with previous studies, that adopted explanatory power is an indicator for measuring the predictive ability of an integrated TAM and TPB model in health professionals' technology acceptance behavior [10]. The study results clearly indicate the important role of self-efficacy and knowledge in positively influencing perceived behavior control. The model highlights the underlying relationships between these variables and the existing C-TAM-TPB variables, providing insights into how the acceptance and use of HIS in nursing can be further explained and facilitated.

The findings of the present study showed that perceived usefulness and perceived ease of use have a significant and positive relationship with nurses' attitudes toward HIS, with a path coefficient of 0.440 ( $p$-value $<0.01$ ) and 0.138 ( $p$-value $<0.05$ ) respectively (thus supporting hypotheses $\mathrm{H} 2$ and $\mathrm{H} 3$ ). The results also indicated a significant and positive impact of perceived ease of use on perceived usefulness, with a path coefficient of 0.536 and $\mathrm{p}$-value $<0.01$ (supporting H4). These findings are consistent with the conclusions of Hung et al. [10] in their study on use of the integrated TAM and TPB model to understand physicians' acceptance of the Medline system. Although the relation between ease of use and usefulness has shown mixed results [57], previous studies have proved that perceived ease of use has a great direct positive effect on perceived usefulness[58], especially in the field of healthcare [20,28]. The above analysis suggests that when nurses operate the HIS, perceived ease of use of the system will influence their perceived level of usefulness of it, and they feel more satisfied with the system's usefulness and usability, thus raising their enthusiasm toward using it. In addition, the expected direct effect of perceived usefulness on intention was not statistically significant $(\beta=-0.039, p-$ value $>0.05$ ), thus not supporting $\mathrm{H} 1$. However, the positive effect of perceived usefulness on intention to use is still controversial [59]. The result is consistent with what Egea and González [47] concluded in their study on using the TAM to explain the physicians' acceptance of EHCR systems.

The study demonstrates that perceived behavior control was significantly influenced by both self-efficacy (H5 was significantly supported; $\beta=0.180, t=4.536, p$-value $<0.01)$ and knowledge $(\mathrm{H} 6$ was significantly supported; $\beta=0.664, t=$ $18.269, p$-value $<0.01$ ). The results add considerably to previous research on user acceptance of technology, by connecting self-efficacy and knowledge variables to the perceived behavior control variable. However, knowledge was shown to have a higher beta value than self-efficacy. This is consistent with the findings of Abroud et al. [43] whose research added self-efficacy and knowledge into perceived behavior by applying the integrated TAM and TPB model. 
Moreover, the explanatory power of the perceived behavioral control is $\mathrm{R} 2=52.9 \%$, implying that the greatest variance in the perceived behavioral control can be explained by self-efficacy and knowledge, and nurses' personal characteristics may influence their perceived level of behavioral control.

This study has shown that attitude towards behavior, subjective norm and perceived behavioral control significantly affect behavioral intention toward use, with path coefficients of $0.361,0.248$ and 0.327 respectively $(\mathrm{H} 7, \mathrm{H} 8$ and $\mathrm{H} 9$ were significantly supported at $p$-value $<0.01)$. The direct positive relationship of attitude, subjective norm, and perceived behavioral control is in line with prior research conducted by Hung et al. [10] and Abroud et al. [43]. Hence, it can be inferred that the intention to use HIS could be increased by stimulating a favorable attitude towards it, applying social pressure, and enhancing the usability of the system. However, attitude toward behavior has been shown to have a higher beta value with respect to the subjective norm and perceived behavioral control. This notion is consistent with the findings of most research using the intention-based model [10,60]. Thus, a favorable attitude needs to be formed in order to stimulate behavioral intentions. In addition, the second higher beta value was related to the path coefficient from perceived behavioral control to behavioral intention $(\beta=0.327)$. This result is consistent with the research results of Hung et al. [10] and $\mathrm{Yi}$ et al. [38] which were conducted in the field of healthcare. In short, nurses' intentions to use an IS would be high when they perceive that it can be controlled effectively.

\section{CONCLUSIONS}

HIS acceptance in nursing is a relatively new line of investigation to nursing researchers in Malaysia. The results imply that the model may be a robust research tool for predicting intentions to use an IS in the context of nursing. This study helps hospitals and researchers understand why nurses use the HIS, and how to increase their acceptance of it by improving the currently used system. A recommendation can be stated that to enhance nurses' intentions toward use of an IS, it should be designed in a more user-friendly way, and nurses must themselves be competent in using it in their work.

\section{REFERENCES}

[1] E.E. Heller, The computer-based patient record vision contrasted with HIS/MIS, International Journal of Bio-Medical Computing, 39 (1995) 19-23.

[2] V. Venkatesh, F.D. Davis, A Theoretical Extension of the Technology Acceptance Model:Four Longitudinal Field Studies Management Science, 46 (2000) 186-204.

[3] C. Abrahamsen, Patient safety: Take the informatics challenge, Nursing Management, 34 (2003) 48-51.

[4] C. Bradley, Technology as a catalyst to transforming nursing care, Nursing Outlook, 51 (2003) S14-S15.

[5] H.W. Lee, T. Ramayah, N. Zakaria, External Factors in Hospital Information System (HIS) Adoption Model: A Case on Malaysia, Med Syst, (2011).

[6] A. Hennington, B. Janz, R. Poston, I'm just burned out: Understanding information system compatibility with personal values and role-based stress in a nursing context, Computers in Human Behavior, 27 (2011) 1238-1248.

[7] H. Karsten, R. Vuokko, Nurses Translating Technology, in: Text and Data Mining of Clinical Documents, 2008, pp. 6880.

[8] H. Mohd, S.M.S. Mohamad, Acceptance Model of Electronic Medical Record, Advancing Information and Management Studies, 2 (2005) 75-92.

[9] A.A. Abdrbo, C.A. Hudak, M.K. Anthony, S.L. Douglas, Information Systems Use, Benefits, and Satisfaction among Ohio RNs, Computers, Informatics, Nursing, 29 (2011) 59-65

[10] S. Hung, Y. Ku, J. Chien, Understanding physicians' acceptance of the Medline system for practicing evidence-based medicine: A decomposed TPB model, International Journal of Medical Informatics, 81 (2012) 130-142.

[11] N.A. Behkami, T.U. Daim, Research Forecasting for Health Information Technology (HIT), using technology intelligence, Technological Forecasting \& Social Change, 79 (2011) 498-508.

[12] D. Abele, G. Vincenzo, P. Simona, C. Paola, P. Tiziana, M. Benedetto, N. Simonetta, S. Gisella, P. Paolo, The impact of a clinical information system in an intensive care unit, Clinical Monitoring and Computing 22 (2008) 31-36.

[13] R.J. Bosman, Impact of computerized information systems on workload in operating room and intensive care unit Best Practice \& Research Clinical Anaesthesiology, 23 (2009) 15-26.

[14] M.L. Bernstein, T. McCreless, M.J. Cote, Five Constants of Information Technology Adoption in Healthcare, Hospital Topics, 85 (2007) 17-25.

[15] A. Ellahi, I. Manarvi, Understanding Attitudes Towards Computer Use In The Police Department Of Pakistan, Electronic Journal of Information Systems in Developing Countries, 42 (2010) 1-26

[16] S. Abedini, A.J.B. Sihes, H.K. Takhti, S. Abedini, Assessing Nursing Curriculum: Graduate Nurse Viewpoints, Canadian Journal of nursing informatics, 6 (2011).

[17] K. Nurten, Factors Affecting Nurses' Attitudes Toward Computers in Healthcare, Computers, Informatics, Nursing, 29 (2011) 121-129.

[18] L.K. Schaper, G.P. Pervan, ICT and OTs: A model of information and communication technology acceptance and utilisation by occupational therapists, International journal of medical informatics, 76 (2007) S212-221.

[19] I.L. Wu, J.Y. Li, C.Y. Fu, The adoption of mobile healthcare by hospital's professionals:An integrative perspective, Decision Support Systems 51 (2011) 587-596.

[20] F.-Y. Pai, K.-I. Huang, Applying the Technology Acceptance Model to the introduction of healthcare information systems, Technological Forecasting \& Social Change, 78 (2011) 650-660.

[21] J.M.O. Egea, M.V.R. González, Explaining physicians' acceptance of EHCR systems: An extension of TAM with trust and risk factors, Computers in Human Behavior, 27 (2011) 319-332.

[22] C.D. Melas, L.A. Zampetakis, A. Dimopoulou, M. Moustakis, Modeling the acceptance of clinical information systems among hospital medical staff: An extended TAM model, Biomedical Informatics (2011). 
[23] K. Mathieson, Predicting user intentions: comparing Technology Acceptance Model with the Theory of Planned Behaviour, Information Systems Research, 2 (1991) 173-191.

[24] F.D. Davis, R.P. Bagozzi, P.R. Warshaw, User Acceptance of Computer Technology: A Comparison of Two Theoretical Models, Management Science 35 (1989) 982-1003.

[25] C.H. Tsai, D.S. Zhu, B.C.T. Ho, D.D. Wu, The effect of reducing risk and improving personal motivation on the adoption of knowledge repository system, Technological Forecasting \& Social Change 77 (2010) 840-856.

[26] N. Jeong, Y. Yoo, T.Y. Heo, Moderating effect of personal innovativeness on mobile-RFID services: Based on Warshaw's purchase intention model, Technological Forecasting \& Social Change, 76 (2009) 154-164.

[27] S. Taylor, P. Todd, Assessing it usage: the role of prior experience, MIS Quarterly, 19 (1995) 561-570.

[28] F.C. Tung, S.C. Chang, C.M. Chou, An extension of trust and TAM model with IDT in the adoption of the electronic logistics information system in HIS in the medical industry, International journal of medical informatics 77 (2008) 324-335.

[29] A.K. Yarbrough, T.B. Smith, Technology acceptance among physicians: a new take on TAM, Medical Care Research and Review, 64 (2007) 650-672.

[30] R.J. Holden, B.T. Karsh, The Technology Acceptance Model: Its past and its future in health care, Biomedical Informatics, 43 (2010) 159-172.

[31] D.H. Shin, Potential user factors driving adoption of IPTV. What are customers expecting from IPTV?, Technological Forecasting \& Social Change, 74 (2007) 1446-1464.

[32] K. Mathieson, Predicting user intention: Comparing the technology acceptance model with the theory of planned behavior, Information Systems Research, 2 (1991) 173-191.

[33] I. Ajzen, The theory of planned behavior, Organizational Behavior and Human Decision Processes, 50 (1991) 179 211.

[34] N.M. Yaghoubi, E. Bahmani, Factors Affecting the Adoption of Online Banking An Integration of Technology Acceptance Model and Theory of Planned Behavior, International Journal of Business and Management 5(2010) 159165.

[35] M.H. Hsu, C.M. Chiu, Internet self-efficacy and electronic service acceptance, Decision Support Systems 38 (2004) $369-381$.

[36] V. Venkatesh, M. Morris, G.B. Davis, F.D. Davis, User Acceptance of Information Technology: Toward a Unified View, MIS Quarterly, 27 (2003) 425-478.

[37] I.L. Wu, J.L. Chen, An extension ofTrust and TAM model with TPB in the initial adoption of on-line tax: An empirical study, International Journal of Human-Computer Studies 62 (2005) 784-808.

[38] M.Y. Yi, D.J. Jackson, S.J. Park, C.J. Probst, Understanding information technology acceptance by individual professionals: Toward an integrative view, Information and Management, 43 (2006) 350-363.

[39] P. Chau, P. Hu, Information technology acceptance by individual profes-sionals: A model comparison approach, Decision Sciences, 32 (2001) 699-719.

[40] S. Taylor, P. Todd, Understanding Information Technology Usage: A Test of Competing Models, Information Systems Research, 6 (1995) 144-176.

[41] C.D. Chen, Y.W. Fan, C.K. Farn, Predicting electronic toll collection service adoption: An integration of the technology acceptance model and the theory of planned behavior, Tramsportation Research Part C: Emerging Technologies, 15 (2007) 300-311.

[42] F.D. Davis, Perceived Usefulness,Perceived Ease of Use, and User Acceptance of Information Technology, MIS Quarterly, 13 (1989) 319-340.

[43] A. Abroud, Y.V. Choong, S. Muthaiyah, Preparation of Measurement Tools of the Effective Factors for the Acceptance of Online Stock Trading, European Journal of Economics, Finance and Administrative Sciences (2010) 34-51.

[44] M. Willmer, How nursing leadership and management interventions could facilitate the effective use of ICT by student nurses, Journal of Nursing Management, 15 (2007) 207-213.

[45] N.M. Yaghoubi, B. Kord, R. Shakeri, E-Government Services and user Acceptance: The Unified Models' Perspective, European Journal of Economics, Finance and Administrative Sciences, (2010) 36-49.

[46] M. Fishbein, I. Ajzen, Belief, attitude, intention, and behavior: An introduction to theory and research, Addison-Wesley, California, 1975.

[47] (!!! INVALID CITATION !!!).

[48] T. Yamane, Statistics, An Introductory Analysis, 2nd ed., New York, 1967.

[49] N. Urbach, F. Ahlemann, Structural Equation Modeling in Information Systems Research Using Partial Least Squares, Information Technology Theory and Application, 11 (2010) 5-40.

[50] C.M. Ringle, M. Sarstedt, D.W. Straub, A Critical Look at the Use of PLS-SEM in MIS Quarterly, MIS Quarterly, 36 (2012) iii-8.

[51] B. Kijsanayotina, S. Pannarunothai, S.M. Speedie, Factors influencing health information technology adoption in Thailand's community health centers:Applying the UTAUT model, International journal of medical informatics 78 (2009) 404-416.

[52] W.W. Chin, The partial least squares approach to structural equation modeling, in: G.A. Marcoulides (Ed.) Modern Methods for Business Research, Lawrence Erlbaum, London, 1998, pp. 295-336.

[53] C. Fornell, D.F. Larcker, Evaluating structural equation models with unobservabl e variables and measurement error, Marketing Research, 18 (1981) 39-50.

[54] A. Bhattacherjee, G. Premkumar, Understanding Changes in Belief and Attitude toward Information Technology Usage: A Theoretical Model and Longitudinal Test, MIS Quarterly, 28 (2004) 229-254.

[55] R.B. Kline, Principles and Practice of Structural Equation Modeling, 3th ed., Guilford Press, New York, 2011.

[56] C. Chiu, H. Huang, C. Yen, Antecedents of trust in online auctions, Electronic Commerce Research and Applications, 9 (2010) 148-159. 
[57] M.Y. Yi, Y. Hwang, Predicting the use of web-based information systems: self-efficacy, enjoyment, learning goal orientation, and the technology acceptance model, International Journal of Human-Computer Studies, 59 (2003) 431-449. [58] Y.H. Cheng, Y.J. Yeh, Exploring radio frequency identification technology's application in international distribution centers and adoption rate forecasting, Technological Forecasting \& Social Change, 78 (2011) 661-673.

[59] V. Terzis, A. Economides, The acceptance and use of computer based assessment, Computers \& Education, 56 (2011) 1032-1044.

[60] T. Ramayah, K. Rouibah, M. Gopi, G.J. Rangel, A decomposed theory of reasoned action to explain intention to use Internet stock trading among Malaysian investors, Computers in Human Behavior, 25 (2009) 1222-1230. 